\title{
Cervical screening in women with classic congenital adrenal hyperplasia: uptake and barriers
}

Journal readers may be aware that population uptake of the National Health Service (NHS) Cervical Screening Programme has been declining in recent years with up to one in four of those eligible for screening not attending. As a result, in 2019 Public Health England launched a national cervical screening campaign to promote uptake. ${ }^{1}$ It has been recognised that certain population groups may experience additional challenges in attending for cervical screening: this may be related to socioeconomic or ethnic factors, disability or age, for example. There have been efforts to facilitate screening in transgender men, and those who have experienced sexual violence. ${ }^{2}$

Healthcare professionals may be able to identify other patient groups who may find cervical screening challenging. As endocrinologists, we hypothesised that women with the condition classical congenital adrenal hyperplasia $(\mathrm{CAH})$, which can cause developmental differences of the genital tract, may also experience barriers, and conducted a population survey to explore this hypothesis.

In brief, $\mathrm{CAH}$ is a rare autosomalrecessive disorder of adrenal steroid synthesis affecting 1 in 10 000-20 000 live births. As well as causing adrenal insufficiency, CAH is associated with adrenal androgen accumulation, which in females results in varying degrees of genital virilisation. Features include clitoromegaly, labial fusion and a shared urethral-vaginal opening, often requiring surgery. In adulthood, 
women with CAH commonly experience vaginal stenosis. ${ }^{3}$

We invited women with a selfreported diagnosis of classical $\mathrm{CAH}$ aged between 25 and 64 years (ie, those eligible for invitation to cervical screening) to complete an anonymous online survey about their cervical screening experiences. This was conducted between 1 January and 1 August 2020 (following appropriate ethical approvals) using the Online Surveys software accessed via a link from the Living with $\mathrm{CAH}$ charity website. Results were compared with population figures from NHS Digital and published population survey data. $^{45}$

In total, 38 respondents were eligible for inclusion in our study. Some $84 \%$ of respondents had undergone previous genital tract surgery, with $79 \%$ describing that vaginal narrowing was a problem in adulthood.

When asked about their last invitation to screening, only $37 \%$ of respondents had attended, compared with $78 \%$ of the general population $\left(p=1.28 \mathrm{E}^{-9}\right){ }^{4}$ Some $39 \%$ stated they had never attended for cervical screening, compared with just 3\% of those questioned in a 2009 population survey $\left(p=1.59 \mathrm{E}^{-24}\right) .^{5}$ When asked about their previous experiences, 39\% of women reported finding the procedure painful or embarrassing, and the procedure could not be completed in $22 \%$ of respondents.

As shown in figure 1 , reasons given for not attending screening included no recent, or only female, sexual partners, a previous painful or unsuccessful experience, and embarrassment about the appearance of their genitals, with some women reporting that healthcare professionals had commented negatively about the appearance of their external genitalia which had deterred them from future examinations. Others had been incorrectly informed that they lacked a cervix and so screening was not indicated.

While national public health campaigns may raise awareness at the population level, healthcare professionals, particularly in the fields of reproductive endocrinology, gynaecology and sexual and reproductive health, have an important role in improving access to these important health interventions in their specialist patient groups. For example, having the procedure performed by an experienced person familiar with their condition was supported by this surveyed group, and we are trying to establish a pathway for this within our region. Notably, only 29\% of respondents reported ever discussing sexual health issues with their specialist care provider.

While this survey reflects a small patient group, we found the results striking and invite journal readers to consider whether there may be similar unmet health needs in their own patients that should be explored.

\section{Kerri Devine $\odot{ }^{1}$ Anna L Mitchell ${ }^{1,2}$}

${ }^{1}$ Translational and Clinical Research Institute, Newcastle University, Newcastle upon Tyne, UK ${ }^{2}$ Department of Endocrinology, Royal Victoria Infirmary, Newcastle upon Tyne, UK

Correspondence to Dr Kerri Devine, Translational and Clinical Research Institute, Newcastle University, Newcastle upon Tyne NE1 7RU, UK; kerri.devine@ nhs.net

Acknowledgements The authors would like to thank the charity Living with $\mathrm{CAH}$ for their support with reviewing and advertising the survey.
Funding The authors have not declared a specific grant for this research from any funding agency in the public, commercial or not-for-profit sectors.

Competing interests None declared.

Patient and public involvement Patients and/or the public were involved in the design, or conduct, or reporting, or dissemination plans of this research.

Patient consent for publication Not required.

Ethics approval Yorkshire \& Humber

- South Yorkshire Research Ethics

Committee (REC reference 19/

$\mathrm{YH} / 0378)$.

Provenance and peer review Not commissioned; internally peer reviewed.

(C) Author(s) (or their employer(s)) 2021.

No commercial re-use. See rights and permissions. Published by BMJ.

\section{Check for updates}

Published Online First 23 November 2020

BMJ Sex Reprod Health 2021:47:153-154. doi:10.1136/bmjsrh-2020-200868

\section{ORCID iD}

Kerri Devine http://orcid.org/0000-00030129-4373

\section{REFERENCES}

1 gov.uk. PHE launches 'Cervical Screening Saves Lives' campaign (press release), 2019. Available: https://www.gov.uk/ government/news/phe-launches-cervicalscreening-saves-lives-campaign [Accessed 26 Oct 2020].

2 Zelin JM, Cadman L, Amara P, et al. The 'My Body Back' Clinic: a specialist cervical screening and sexually transmitted infection testing clinic for women who have been sexually abused. J Fam Plann Reprod Health Care 2017;43:327-30.

3 Nordenström A, Frisén L, Falhammar $\mathrm{H}$, et al. Sexual function and surgical outcome in women with congenital adrenal hyperplasia due to CYP21A2 deficiency: clinical perspective and the patients' perception. J Clin Endocrinol Metab 2010;95:3633-40.

4 NHS Digital. Cervical Screening Programme, England - 2018-19, 2019. Available: https://digital.nhs.uk/dataandinformation/publications/statistical/ cervical-screening-annual/england--2018-19

5 Waller J, Bartoszek M, Marlow L, et al. Barriers to cervical cancer screening attendance in England: a populationbased survey. J Med Screen 2009;16:199_ 204. 